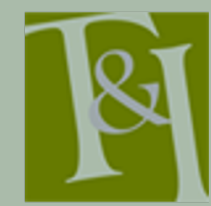

The International Journal for Translation \& Interpreting Research trans-int.org

\title{
Translation and language learning as policy options: Questions of costs and literacy development
}

\author{
Anthony Pym \\ The University of Melbourne \\ anthony.pym@unimelb.edu.au
}

DOI: 10.12807/ti.113201.2021.a02

\begin{abstract}
It has been claimed that the provision of translation and interpreting services curtails the motivation of immigrant groups to learn host languages and thus constitutes an unjustified social cost. Studies with asylum seekers nevertheless show no evidence for such a relation, while studies in healthcare indicate that the targeted use of interpreters, mediators and bilingual providers can reduce overall healthcare costs. To make sense of this evidence in terms of language policy, it is argued in this paper that translation and interpreting cannot be seen as an isolated communication solution but must be analysed alongside a series of situational factors: relative access to alternative mediation strategies, the situated building of trust, the risks associated with each interaction, and the length of the intended stay in the country. It is more generally argued that, in many situations, translation and language learning can go hand in hand, since both enhance literacy.
\end{abstract}

Keywords: Language policy; translation policy; healthcare communication; literacy

\section{Introduction: The problem of translation vs. language learning}

In 2020, in times of COVID-19, residents of nine multilingual housingcommission towers in Melbourne were placed in mandatory lockdown. They were provided with food and information in their languages, probably not enough of either. Australian Senator Pauline Hanson then objected vociferously that the people in the towers were drug addicts being supplied with free drugs by the government and, by the same implacable logic, were non-English speakers who "don't know what the hell to do" and were being supplied with the linguistic equivalent of free government drugs: "We should not be putting out literature in their own language. Learn to speak English when you come here to this country" (Graham, 2020).

Senator Hanson's assumption of an ideological opposition between translation services and language learning, with its underlying appeal to economic sense, was not without precedent. In 2013, Eric Pickles, the UK Secretary of State for Communities, ordered that translations not be provided for immigrants because translation services "have an unintentional, adverse impact on integration by reducing the incentive for some migrant communities to learn English" (Pickles, 2013). Here is his reasoning:

Stopping the automatic use of translation and interpretation services into foreign languages will provide further incentive for all migrant communities to learn 
English, which is the basis for an individual's ability to progress in British society. It will promote cohesion and better community relations. And it will help councils make sensible savings, at a time when every bit of the public sector needs to do its bit to pay off the deficit. (Pickles, 2013)

In a commonsense world, that argument sounds fine: if someone receives free translations all the time, why would they want to learn the host language? In such a situation, language learning would be an irrational allocation of resources. This identification of language learning as the prime goal had received support from then UK Prime Minister David Cameron, who in 2011 argued that all immigrants should learn English (Cameron 2011) and who in 2016 allocated funds specifically for Muslim women to learn English (Cameron 2016). So, what could possibly be wrong?

The first problem, I suggest, is that no evidence has been produced to support the suppositions about translation. If the disincentive resulting from translations is really all that clear, and if the cost is really unjustified, why not put some numbers to the relations? A second problem, which is more serious, is that the initial dichotomy does not stand up to close scrutiny: in terms of policy options, language learning is not necessarily the opposite of translation.

Here I will venture along both those tracks: first some numbers, then the concepts, and finally a call for a concept of translation that saves costs by developing literacy.

\section{Analysing costs}

Ethical ideals are very noble, but at the end of the day, government policy is about distributing resources. When Mr. Pickles launched his argument against translation, it did actually include a number: "local authorities alone spend nearly $£ 20$ million a year translating a variety of documents" (2013). So, what might this number be compared to? Instead of any comparison, Mr. Pickles simply offered the wartime rhetoric of an economy under attack: "every bit of the public sector needs to do its bit" (2013).

Now, if we can show that translation services can actually reduce public costs rather than add to them, we might stand a chance of getting Mr. Pickles, and perhaps even Senator Hanson, to think twice, if not entirely change their minds.

So, can translation save money? Here I approach the question through case studies rather than the logic of any abstract reasoning. There are three kinds of evidence available: 1) anecdotes, of the kind that sometimes make headlines, often concerning legal costs tied to the murky details of out-of-court settlements; 2) studies of hospital costs of patients with limited abilities in a host language; and 3) studies of the ways translation and interpreting services are actually used in complex encounters such as the prolonged detention of asylum seekers. Of those three kinds of evidence, only the medical studies seriously advance the quantitative argument that translation can save money. Yet, the others add qualities.

\subsection{The anecdotes}

It is not hard to find expensive mistakes that have been attributed to translation errors. Columbus, for example, correctly estimated the distance from Spain to India, which is why he was sure he had arrived in the Indies, and why we still talk about the West Indies and cowboys and Indians. The cause lies in a translation of the Arabic mile (1,973 meters) as being the same as the Roman 
mile (1,480 meters) (Fischer, 1975, p. 164). The huge historical misunderstanding can be attributed to a simple translation error. Think of all the confusion that could have been saved!

A similar confusion of units, this time between imperial and metric measurements, was apparently responsible for the loss of the Mars Climate Orbiter in 1999, resulting in a reported cost of US\$327.6 million (Siddiqi, 2018, p. 208).

Other famous anecdotes concern apparent mistranslations of political speeches. There is, for example, the notorious 2009 "Reset" button that Hillary Clinton presented to Russian Foreign Minister, Sergey Lavrov, where the English was rendered as Peregrizka, meaning something like "Overload" (Clinton, 2009). The political costs may have been considerable.

A few of the oft-repeated stories are rather more serious. In 1980, Willie Ramirez was unconscious when admitted to a Florida hospital. His Spanishspeaking friends and family told a bilingual hospital worker that he was intoxicado (suffering from food poisoning), which was translated as 'intoxicated' (drunk). Delay in getting the correct treatment left Ramirez quadriplegic and resulted in a malpractice settlement of approximately US\$71 million (Price-Wise, 2015).

Websites are full of similar cases, some apocryphal, but not all. Is the lesson really so clear? After all, Columbus was a global success and may have used the mistranslation to get financing for his voyage (Fischer 1975, p. 164); Hillary Clinton managed to make a joke of the mistake (Clinton, 2009); and in the Willie Ramirez case, the mistranslation was compounded by problems of culture, stereotype and prejudice (Price-Wise, 2015). When all is said and done, the percentage of major errors is very small when compared with the myriad acts of translation performed each day all over the world. Looking at damages generated in relation to technical and medical translations from 2000 to 2017, Canfora and Ottmann (2018) find only 23 damage-claim events, with only one resulting in a death and only two leading to "minor accidents", and in almost all cases translation was just one of several contributing factors. From one or two disasters, it certainly does not follow that all mistranslations are costly. Some are high-stakes, most are low-stakes, and the difference is important.

The basic argument to be made on the basis of these cases is that, when and where mistakes can be costly, it is worth paying for highly trained professional translators and interpreters so that error can be avoided. That is a very valid argument in any situation where translation mistakes can have considerable negative consequences, which makes healthcare a prime area of interest.

That general argument, however, merely pits low-effort translation (for low-stakes situations) against high-effort translation (for high-stakes situations). It does not compare translation itself with any other policy option.

\subsection{Healthcare interpreters}

Hospitals are expensive, and in any country with a public health system, the cutting of costs could be beneficial for the public purse. At the same time, any reduction in costs has to be weighed against potential reductions in quality of life, assuming that quality of life is the aim of the system in the first place. Not surprisingly, healthcare is the area in which we find the most serious studies of the way language services relate to costs. Further, these studies are able to compare the use of translation with the use of various forms of non-translation.

I am in no position to give an account of all the research that has been conducted on the use of interpreters in healthcare provision. Nevertheless, we 
can lean on Flores' 2005 review of some 36 such studies of English-language health services, which concludes that "multiple studies document the positive impact that both trained, professional interpreters and bilingual providers have on LEP [Limited English Proficiency] patients' quality of care" (2005, p. 255). That is, benefits come both from mediation by interpreters and from medical staff speaking a language that the patient understands well (the major example in the studies is Spanish in the United States). Translation is not alone - if there is a bilingual healthcare provider in the mix, there has been some language learning going on somewhere.

Flores $(2005$, p. 295) reports that LEP patients who have trained, professional interpreters differ from those who do not receive such services in that they:

- Make more outpatient visits

- Receive and fill more prescriptions

- Do not differ from English-proficient (EP) patients in test costs or receipt of intravenous hydration

- Are less likely than EP patients to have laboratory tests done

- Have outcomes among those with diabetes that are superior or equivalent to EP patients

- Have high satisfaction with care.

On the other hand, LEP patients who have bilingual providers differ from those who do not have a bilingual provider or an interpreter in that they:

- Ask more questions

- Have better overall information recall

- Are more comfortable discussing sensitive or embarrassing issues (we will briefly discuss this below)

- Have less pain and better physical functioning, psychological wellbeing, and health perceptions among those with hypertension or diabetes

- Have high patient satisfaction.

One might thus conclude that interpreters and bilingual staff are both beneficial solutions. Further, it would be difficult to identify a metric that could definitively prove that one is somehow more efficient than the other: both kinds of solutions can be good when available; both prove beneficial in slightly different ways.

The most significant large-scale research in this field appears to be Lindholm et al. (2012), which analysed the hospital stays of 3,071 patients with limited English proficiency. These were all the LEP patients admitted to "a tertiary care hospital" over a period of three years, in a context where $39 \%$ of them received interpreting services at admission and discharge. The researchers found that the length of hospital stay for LEP patients was significantly shorter when professional interpreters were used either at admission only or at both admission and discharge. The reduction in the length of stay was between 0.75 and 1.47 days $(\mathrm{p}<0.02)$. Further, "patients receiving interpretation at admission and/or discharge were less likely than patients receiving no interpretation to be readmitted within 30 days" (2012, Abstract).

These are numbers we can compare. The savings are fairly clear if you bear in mind that the average cost for a day in hospital in the United States in 2013 ranged from US $\$ 1,791$ to US\$2,289 (Rappleye, 2015), while the average 
payment for a translator or interpreter in a US hospital at the time was US\$22.08 an hour (Bureau of Labor Statistics, 2014). To venture a very rough calculation, an interpreter would have to spend about 80 hours with a patient before the costs of interpreting exceeded the costs of the saved time in hospital.

That is perhaps all we have to show the likes of Senator Hanson and Mr. Pickles: interpreting services can save money.

As convincing as Lindholm et al. (2012) sound, other studies appear to contradict their findings. Wallbrecht et al. (2014) looked at 124 patients with limited English proficiency, 58\% of whom used interpreters. In this case, it was found that "patients with LEP who used interpreters had a significant increase in LOS [Length of Stay] compared with those who did not use interpreters" (2014: Abstract). How can the divergent findings be explained? One notes that Lindholm et al. looked at almost 25 times the number of patients, so it might stand a chance of being 25 times more significant - the smaller the study, the greater the risk of the anecdotal. But then, the use of interpreters was significantly more frequent in the smaller study: $58 \%$ (in Wallbrecht et al.) as opposed to $39 \%$ (in Lindholm et al.). It may be that the reduction in overall costs in Lindholm et al. was partly due to a more targeted use of interpreting services.

So, the general argument in this field would be that the use of professional interpreters can lead to greater understanding by the service user and thus to lower costs. But a secondary argument could be that the benefits of professional mediation are enhanced by targeting high-stakes interactions where correct understanding is key, then using cheaper solutions in other situations.

Note also that Jacobs et al. (2007) looked at 223 Spanish-speaking hospital patients, using a research design that compared "enhanced interpreting services" with "normal interpreting" and the experience of 100 Englishspeaking patients (so there is no indication of the percentage of Spanishspeaking patients receiving no interpreting). The study found that enhanced interpreter services did not significantly reduce the associated costs. However, having a Spanish-speaking doctor significantly increased patient satisfaction and resulted in fewer Emergency Department visits, "thereby reducing costs by $\$ 92$ per Spanish-speaking patient over the study period [of three months]" (2007, Abstract). So, in this case, the greater benefits appear to have come from bilinguals providing key services - which logically requires that languages have been learned prior to the encounters.

To say that people are happier and understand better when communicating in their L1 is certainly nothing to write home about. The establishing of trust has long been recognized as an essential part of bilingual healthcare (Greenhalgh, Robb \& Scambler, 2006; Hsieh et al., 2010, for example). If people can share a common language, they will tend to do so; when not, they might look for a mediator. Kuo and Fagan (1999) found that Latino LEP patients report "greater levels of comfort" discussing sensitive issues or embarrassing subjects with bilingual physicians or when family members or friends interpret (see also the virtues of non-professionals discussed in Hlavac, 2011, Martínez-Gómez, 2015, Pokorn and Mikolič Južnič, 2020, for example). Yet, even this apparently obvious conclusion requires a hedge. Espin (2013, p. 138) reports that the use of $L 2$ may be more satisfactory in some cases: "Interviewees stated repeatedly that the second language facilitates ease of communication when the topic discussed is sexuality. [...] Feelings of shame, they reported, would have prevented them from addressing these topics in depth had they used their first language." In such cases, the absence of mediation may be a decided advantage, as might the gaining of competence in L2. 
It follows that not everyone wants translation services all the time, even when translation can save costs.

\subsection{Interpreters for asylum seekers}

Within the frame of the European project Mobility and Inclusion in Multilingual Europe (MIME), in 2014-15 Nike Pokorn in Ljubljana and Sabine Fiedler in Leipzig led teams doing small-scale studies on the ways asylum seekers solve communication problems (reported in Pokorn and Čibej 2018a, 2018b, Fiedler and Wohlfarth 2018, and Pym 2018). The researchers asked about a range of possible solutions, including online automatic translations, the use of lingua francas, mediation via professional interpreters, and intercomprehension (conversations in two languages, where each person has passive competence in the language of the other). These studies then make comparisons between the communication solutions that users actually choose. To some extent, it is possible to estimate the relative costs of each solution, but the significant differences lie in the way the communication situation is itself constructed. The key variable was found to be the kind of mobility concerned. To simplify, if the mobile subject is planning to spend years in a place, then they logically learn the language(s) of that place; if, however, they are involved in a high-stakes one-off encounter (such as initial screening for asylum eligibility), then investment in a professional translator or interpreter is clearly warranted and often sought. To that extent, language learning is indeed operating as a kind of opposite of translation. Note, though, that there are many degrees to which both kinds of solution can be employed, with very significant effects on costs: online technologies (with speech recognition) offer approximate translations that are virtually free; intercomprehension means that you only require passive competence in L2 or L3; and the learning of a lingua franca can extend efficiency over vast stretches of time and space.

Interestingly, these interview-based studies bring out a range of key qualitative variables, all of which can be seen as kinds of costs: linguistic accuracy, degrees of social inclusion, and the relative independence of the user.

Of the 18 asylum-seekers interviewed in Leipzig, only five had used official interpreters (for contact with authorities and for medical visits), while two others had used friends as interpreters. Perhaps surprisingly, six stated that they did not want to use interpreters, while others expressed outright distrust of them. The main arguments against interpreters were their unreliability and the asylum seekers' reluctance to be dependent on them. For these reasons, all the interviewees said they were learning German rather than communicating through interpreters.

In Ljubljana, the eleven interviewed asylum-seekers had all had official interpreters present at their admission interviews. In other situations, however, only one respondent reported having an interpreter present when visiting the doctor, while others relied on friends or family members as mediators. Ten of the eleven respondents said they would still learn Slovene if they had the opportunity to use an official interpreter at all times, basically because of their desire to be independent.

All of these interviewees, when asked directly about it, stated that they would still learn the host languages even if they had constant access to professional translation and interpreting. Nationalist politicians would presumably be pleased with the language learning, although perhaps not with the causes: these studies found no evidence at all that translation services diminish the desire to learn host languages. The reasons given were not just that the host languages were useful in themselves, and not just because the 
respondents were saying what they thought the researchers wanted to hear (although the probability of a white-coat effect remains considerable): as indicated above, the reason was fairly consistently that the mediators themselves were not entirely trusted (in a context where the asylum seeker has to show that their motivations are political and not economic) and that dependence on them restricted the asylum-seekers' agency. If mistakes are going to be made, the mobile subjects sometimes prefer to make them themselves - in a host language, in a lingua franca, through intercomprehension, using free online translation technologies or with the help of family members.

That logic should be factored into the question of costs. Professional translation and interpreting services can reduce financial costs in high-stakes situations like healthcare encounters, but they may incur a range of other costs in situations where the stakes are not so high or, more significantly, where the service user has access to a range of alternative communication solutions.

This is where attempts at quantitative analyses require a rethinking of the concepts in play.

\section{Analysing concepts}

"Why have language policy? Why shouldn't languages be left to grow like grass in the fields?" So asked the critical sociolinguist Florian Coulmas over lunch. It did not take long for me to reply, since I had thought about the question: because, in the age of political modernity, governments run schools, so the key instrument of language policy is the selection of which languages are used and taught in public schools. Everything else must be seen in relation to that: language learning is the main instrument of policy, and the main public expenditure to be accounted for. Why? Because shared languages are required for the development of a literate polity that can enter freely into public debate, and they are thereby required for the possibility that all citizens can, in theory, presume co-authorship of their laws (Habermas, 1995, p. 130). That is a high ideal, but a necessary one for any language policy that cares about democracy.

Thinking from that perspective, there is something slightly worrying in a view that focuses on translation alone, as if translation required a policy of its own. On one level, the need for policymakers to take translation into account is a banal truism: between languages, one finds translation, non-translation, or partial translation (just as humans either breathe, don't breathe, or breathe badly, sometimes with the help of machines). However, most language policies do not have translation as a particular focus of attention (just as most accounts of humanity do not particularly mention breathing): the prime aim is to maintain a configuration of one or several official languages in public education, and translation then enters as an afterthought, as a tool to achieve that aim - or indeed to be marginalized in cases where the aim is complete monolingualism. Translation is there, but it is not the only type of action there, and it is mostly not the most important of all the possible actions. A general language policy also has implications for a lingua franca policy, intercomprehension policy, official standardization policy, and so on. But mostly, and as a centrepiece of the public education that comes with political modernity, there is no language policy without a language-learning policy, without decisions about which languages are to be used and taught in public schools.

As I have argued elsewhere, in terms of transaction-cost analysis (Pym $1995,2013)$ translation comes into its own as a short-term measure, a stopgap, a bridging device, since the longer-term relations between languages are more 
efficiently handled by various forms of more generalized language learning. On this view, as mentioned above with respect to asylum seekers, the key factor is time: if the encounter is one-off, then use translations; if it is one of a series that is likely to last for years, then start learning languages.

A slightly more sophisticated analysis is offered by the rationalisms of risk management (Pym 2015), which come closer to the kinds of variables that users intuitively consider when deciding what kind of communication solution to use: according to the model, users estimate the cost of failed communication (communication risk) and the cost of betrayal by the mediator (credibility risk), while the translator gauges the variability of linguistic solutions (uncertainty risk), then they all distribute their efforts accordingly. As we have seen above, the higher the stakes over time, the greater the investments that can rationally be made. Risk analysis can thus factor in many of the variables that we have seen to be important to service users, over and above the simple time dimension.

Seen in sociological terms, the problem of comparing costs can be made much simpler. On one level, the entire range of multilingual communication solutions can be reduced to variables of language learning: the use of a lingua franca means everyone learns a common language; intercomprehension requires that we teach passive competence in a range of cognate languages; translation implies that only special social groups will receive training in the languages concerned (possibly groups from other societies); and translation technologies should require that everyone receives training in how to use them (but since they are generally regarded as cheat cribs, as some kind of opposite of proper learning procedures, that training is lamentably hard to find). So, it can be boiled down to who learns which languages. This view allows one to see how a decision in one area has consequences for all others. For example, the Latvian government has successfully developed a public machine-translation system. Operative from 2014 for Latvian, Russian and English, it certainly represents a significant investment in translation as a policy instrument. But why should Latvia, of all countries, take this course of action? It escapes no one that the technological enlightenment is mainly addressed to the L1 Russianspeaking citizens, who comprise about a third of the population and many of whom are not proficient in Latvian, which is the only official language. The machine translation system is thus explicitly for social inclusion, albeit in the political context of denying official status to Russian, thus further ensuring that Russian is not a vehicular language in public schools.

The question is then not actually one of translation versus language learning, but of restricted-group language learning (for the training of translators and interpreters) versus more general language learning (for all the other solutions), with a range of quantitative degrees in between.

Once you see that relation, many of the simpler binary claims simply look strange. Take arguments that pit translation against monolingualism, for instance. Grin (2010) claims that translation should be supported by public policy because translation enhances linguistic diversity, just as linguistic diversity is needed for translation to exist. So, we should apparently rub each other's backs: "it is in the interest of translators and interpreters to enter the fray and become explicitly supportive of language policies in favour of multilingualism - as well as of the research that provides the ammunition for such language policies" (2010: 16). Well, no: linguistic diversity is enhanced by diversity in language acquisition, and only then by translation as a consequence of not everyone acquiring the same languages.

When you look closely, the conceptual separation of translation and language learning is precarious. If the two were indeed absolute opposites, as 
Senator Hanson and Mr. Pickles would have it, then the growth of English as a lingua franca should be accompanied by a decline in the global demand for translations (if people all speak the same language, why would they need translations?). In fact, according to all the numbers (Pym 2006, 2008), as the number of L2 speakers of English rises, so does the global demand for translations - both at the same time. A more sophisticated explanation is thus required, fundamentally concerning the different directionalities involved. A similar paradox surfaced when I was using UNESCO data to map book translation flows between languages (Pym 2004, pp. 43-44). It was no surprise that the languages with fewer books had the higher percentages of translations to non-translations (if you don't publish much, you translate a lot), but it was surprising that the countries with the highest percentages of translations to nontranslations also tended to be the ones with the highest percentages of publications in non-national languages. In Sweden, for example, some $22 \%$ of all books published were translations (compared with less than $4 \%$ of translations among books published in the United States or the United Kingdom) and some $16 \%$ of all books were published in languages other than Swedish. That is, countries that consume a lot of translations also tend to read a lot in foreign languages - cultural openness appears to work on several levels at once. On that macro level, the nationalist politicians' assumed opposition clearly does not hold.

Seen in these terms, the policy options are not well formulated as a choice between translation and language learning. Both approaches must be thought of together. And the key variable becomes not just translation, but the specific modes and uses of translation in relation to the modes of mobility and inclusion. The prime error would be to assume that translation is just one thing, and that communicative situations are all the same.

Here I would like to close with a suggestion drawn from the field of healthcare interpreting. I started looking at healthcare on the assumption that the situations were high-cost, which is why I found the research on comparative monetary expenses. But in the process, I also found something else.

\section{Translation as literacy development}

Studies on language services in healthcare increasingly describe their aim as being to enhance 'health literacy', usually defined as "the degree to which individuals have the capacity to obtain, process and understand basic health information and services needed to make appropriate health decisions" (NielsenBohlman et al., 2004, p. 3). In other words, you provide communication that helps people make their own decisions. In public policy, the concept seems to have its origins in the United States, where it has long functioned as an ideological surrogate for English as an official language: 'literacy' is certainly the word used in laws on "literacy in the English language" (e.g. the National Literacy Act of 1991 and the Adult Education and Family Literacy Act of 1998). No one in the United States (or probably anywhere) could ever argue against literacy, and so the term has spread far and wide. The basic concept can nevertheless be liberated from those origins in the imposition of English: literacy can be seen as the ability to use information in order to make responsible decisions in any field whatsoever, regardless of the languages concerned. Indeed, such an aim could ultimately be compatible with citizens feeling they are "co-authors" of their laws since some kind of political literacy would require precisely that level of informed decision-making. 
In the current context, I find the model of health literacy attractive for two main reasons: first, it posits that learning a natural language system (a langue) is not enough, since many people speak an official language but do not have basic health literacy in it; second, it allows that appropriate information need not be in just one language: people can theoretically have acceptable health literacy in English, Spanish, or any other language that they understand, no matter what the official language of the institution.

The importance of these two points is made clear in reports like the following:

Only 33 per cent of people born overseas have adequate or better health literacy compared to 43 per cent of the Australian-born population. This figure drops to 27 per cent for those who arrived in Australia during the past five years and to 26 per cent for people whose first language is not English. (Ethnic Communities' Council of Victoria 2012, p. 12)

Note carefully: health literacy is certainly a problem that concerns LEP immigrants ( $26 \%$ is worrying), but it also concerns non-immigrant L1 English speakers ( $43 \%$ is nothing to be proud of). The difference is a question of degree, not of a black-and-white divide between one language system and another. Literacy development may be a goal across the board, within the general provision of health services, and only then with respect to translation as a part of those services.

Seen in these terms, literacy might become a very interesting ethical goal for translation, and indeed for all forms of mediation. The aim of translation is then not just to render a foreign text, but to help people actually use the knowledge productively. Interestingly, for the problems we are grappling with here, this way of thinking prompts us to see translation not only as just one of a range of communication modes, but as a mode whose aim is always partly pedagogical: if you are developing literacy, then you are teaching, and you are doing so while you are translating. Once again, translation cannot be separated from learning how to use language.

The point has been made to me in a slightly different way in South Africa. The country's ambitious translation policy is too often seen as concerning how many texts reach how many languages, while the more important question is often what kind of translation is employed. Since the levels of literacy (in the general sense of an ability to make informed decisions) are very different in the various communities, the goal in many cases must be not just to reproduce established texts, but to make them accessible. From that perspective, again, translation is not just one thing. What really matters is the way translations are being presented and used.

Examples of literacy-raising translation are not hard to find in the medical field, particularly in the work of interpreters who are aware of patients' backgrounds and needs. Cortabarria (2016: 104-107) analyses examples like the following:

Doctor: Have they done an endoscopy? Interpreter: ¿Han visto dentro con una cámara?

[Have they looked inside with a camera?]

Here the interpreter explains what the technical term means: the next time the patient hears endoscopy (or indeed endoscopia), they will hopefully know what it means. 
Doctor: Do you have incontinence?

Interpreter: ¿Tiene problemas con incontinencia, con mojarse?

[Do you have problems with incontinence, with wetting?]

This time there is a direct translation of the English term, followed by an explanation to make sure the term is understood.

Doctor: $[. .$.$] in that case he may have Down syndrome.$

Interpreter: [...] en ese caso puede tener Down syndrome.

Here non-translation of the technical term might also be seen as part of a pedagogical discourse: these are the English words that you are going to hear around you.

Many further solutions are found along the continuum from full translation to full teaching. In interpreting, they tend to be produced intuitively, in accordance with the very particular conditions of each encounter. In written translation, one might seek similar solutions, where translation is used to make languages unavoidably present to each other, or mixed, rather than in separate publications or on different electronic screens. On the level of policy, perhaps the main lesson to be learned is that translators (including interpreters) can do more than translate, and there are often good ethical reasons for them to do so.

Admittedly, healthcare is a field with its specific risks and justifications. The kind of wider understanding of translation that makes sense there is not easily sought in the courtroom, for example. Yet, the legal field includes encounters like interpreter-mediated interactions between attorneys and the accused, where the development of a certain legal or courtroom literacy can certainly be seen as a legitimate ethical aim, firstly of the global interaction, and then of translation as part of that interaction. Beyond that, we might want to talk about economic literacy, technological literacy, academic literacy, translation literacy and the rest, right through to the political literacy so critically required by our modernity.

\section{Conclusion}

We have seen the claim that translation and language policy should have as their shared aim the maintenance of language diversity. That is a very noble ideology, based on a speculative ecology of cultures and a few putative expressions of political will, mostly inscribed in old treaties where people envisaged European languages as being the only ones entering into mutual protection. Our world is now very different: multiple mobilities have brought superdiversity into our cities, and the most vexing ethical question is now probably whether or not people have the right to abandon languages, if they want to, in favour of more standardised languages (as argued by Ginsburgh \& Weber, 2011). Let languages live and die like grass in the fields? Why not?

I have suggested that public education is the reason why not, and the many literacies of our lives must be the applications and extensions of that education. Diversity itself is not sufficient as an ethical aim. Our language policies should instead be focused on giving people the tools they need in order to participate in inclusive democracies, and those tools need not be whole languages.

I have tried to make several general points along these lines: 
- Translation must be analysed alongside other communication solutions, the main ones being language learning and literacy development;

- There is no evidence that the provision of translation services blocks language learning, whereas there is some evidence that users in longterm situations prefer to learn languages rather that depend on translators;

- Translation situations are not uniform: some are high-stakes, most are low-stakes, and that difference must be accounted for in policy;

- In high-stakes situations, translation can produce cost savings, but so can the training of communication partners, who can become reasonably bilingual (through language learning) and have specific skills in cross-cultural encounters (through specific literacy development);

- Translation and language learning can go hand in hand, since both enhance literacy.

On these many levels, it makes little sense to isolate translation from language learning, and it is nonsense to suppose, as might Senator Hanson and Mr. Pickles, that translation is the opposite of language learning.

\section{References}

Bureau of Labor Statistics (2014). Occupational employment and wages, 27-3091 Interpreters and translators. Retrieved from https://web.archive.org/web/ 20141008054215/https://www.bls.gov/oes/current/oes273091.htm

Cameron, D. (2011). Speech on immigration. Retrieved from https://www.gov.uk/ government/speeches/prime-ministers-speech-on-immigration

Cameron, D. (2016). We won't let women be second-class citizens. The Times January 18, 2016. Retrieved from https://www.thetimes.co.uk/article/we-wont-letwomen-be-second-class-citizens-brh0716jttb

Canfora, C., \& Ottmann, A. (2018). Of ostriches, pyramids, and Swiss cheese. Risks in safety-critical translations. Translation Spaces, 7(2), 167-201.

Clinton, H. R. (2009). Remarks with Russian Foreign Minister Sergey Lavrov. US Department of State. Retrieved from https://2009-2017.state.gov/secretary/ 20092013clinton/rm/2009a/03/120124.htm

Cortabarria, B. (2016). Non-standard Spanish in the United States and translation norm behavior: A study of hospital and court interpreters. Doctoral dissertation. Universitat Rovira i Virgili.

Ethnic Communities' Council of Victoria (2012). An investment not an expense: enhancing health literacy in culturally and linguistically diverse communities. Carlton, Victoria: Ethnic Communities' Council of Victoria.

Espin, O. (2013 [1999]). Women crossing boundaries. A psychology of immigration and transformations of sexuality. London and New York: Routledge.

Fiedler, S., \& Wohlfarth, A. (2018). Language choices and practices of migrants in Germany: An interview study. Language Problems and Language Planning, 42(3), 267-287.

Fischer, I. (1975). Another look at Eratosthenes' and Posidonius' determinations of the Earth's circumference. Quarterly Journal of the Royal Astronomical Society, 16, 152-167.

Flores, G. (2005). The impact of medical interpreter services on the quality of health care: A systematic review. Medical Care Research and Review, 62(3). 255-299.

Ginsburgh, V. \& Weber, S. (2011). How many languages do we need? The economics of linguistic diversity. Princeton NJ: Princeton University Press. 
Graham, B. (2020). 'Don’t speak English': Hanson's rant. The Bulletin 6 July. Retrieved from https://www.themorningbulletin.com.au/news/dont-speak-english-hansonsrant $/ 4051158$

Greenhalgh, T., Robb, N. \& Scambler, G. (2006). Communicative and strategic action in interpreted consultations in primary health care: A Habermasian perspective. Social Science \& Medicine, 63, 1170-1187.

Grin, F. (2010). Translation and the dynamics of multilingualism. Cahier de recherche élf 3. Université de Genève, Observatoire élf.

Habermas, J. (1995). Reconciliation through the public use of reason: Remarks on John Rawls's political liberalism. The Journal of Philosophy, 92(3), 109-131.

Hlavac, J. (2011). Sociolinguistic profiles of users and providers of lay and professional interpreting services: The experiences of a recently arrived Iraqi language community in Melbourne. Translation \& Interpreting, 3(2), 1-32.

Hsieh, E., et al. (2010). Dimensions of trust: The tensions and challenges in providerinterpreter trust. Qualitative Health Research, 20(2), 170-181.

Jacobs, E. A., Laura S. Sadowski, L. S. \& Rathouz, P. J. (2007). The impact of an enhanced interpreter service intervention on hospital costs and patient satisfaction. Journal of General Internal Medicine, 22 (Suppl 2), 306-311.

Kuo, D., \& Fagan, M. J. (1999). Satisfaction with methods of Spanish interpretation in an ambulatory care clinic. Journal of General Internal Medicine, 14, 547-50.

Lindholm, M, Hargraves, J. L., Ferguson, W.J. \& Reed, G. (2012). Professional language interpretation and inpatient length of stay and readmission rates. Journal of General Internal Medicine, 27(10), 1294-1299.

Martínez-Gómez, A. (2015). Non-professional interpreters. In H. Mikkelson \& R. Jourdenais (Eds.) The Routledge handbook of interpreting (pp. 417-431). London and New York: Routledge.

Nielsen-Bohlman, L., Panzer, A. M., \& Kindig, D. A. (Eds) (2004). Health literacy: A prescription to end confusion. Washington DC: The National Academies Press.

Pickles, E. (2013). Translation into foreign languages. Written Ministerial Statement by Communities Secretary Eric Pickles on the use of translation services by local authorities. Retrieved from https://www.gov.uk/government/speeches/. translation-into-foreign-languages

Pokorn, N. \& Čibej, J. (2018a). Interpreting and linguistic inclusion - friends or foes? results from a field study. The Translator, 24(2): 111-127.

Pokorn, N. \& Čibej, J. (2018b). 'It's so vital to learn Slovene'. Mediation choices by asylum seekers in Slovenia. Language Problems and Language Planning, 42(3), 288-307.

Pokorn, N. K. \& Mikolič Južnič, T. (2020). Community interpreters versus intercultural mediators. Is it really all about ethics? Translation and Interpreting Studies, 15(1), 80-107.

Price-Wise, G. (2015). An intoxicating error: Mistranslation, medical malpractice, and prejudice. Pennsauken, NJ: Bookbaby.

Pym, A. (1995). Translation as a Transaction Cost. Meta, 40(4), 594-605.

Pym, A. (2004). The moving text: Localization, translation and distribution, Amsterdam \& Philadelphia: John Benjamins.

Pym, A. (2006). Globalization and the politics of translation studies, Meta 51(4), 744757.

Pym, A. (2008). Translation vs. language learning in international institutions: Explaining the diversity paradox, Cultus, 1(1), 70-83.

Pym, A. (2013). Translation as an instrument for multilingual democracy. Critical Multilingualism Studies, 1(2), 78-95.

Pym, A. (2015). Translating as risk management. Journal of Pragmatics, 85, 67-80.

Pym, A. (2018). Why mediation strategies are important. Language Problems and Language Planning, 42(3), 255-266.

Rappleye, E. (2015). Average cost per inpatient day across 50 states. Retrieved from https://www.beckershospitalreview.com/finance/average-cost-per-inpatient-dayacross-50-states.html 
Siddiqi, A. A. (2018). Beyond Earth: A chronicle of deep space exploration, 1958-2016. Washington DC: NASA History Program Office.

Wallbrecht J., Hodes-Villamar, L., Weiss, S. J., \& Ernst, A. A. (2014). No difference in emergency department length of stay for patients with limited proficiency in English. Southern Medical Journal, 107(1), 1-5. 


\section{University Library}

\section{- M M N E R VA A gateway to Melbourne's research publications}

Minerva Access is the Institutional Repository of The University of Melbourne

Author/s:

Pym, A

Title:

Translation and language learning as policy options: Questions of costs and literacy development

Date:

2021-01-01

Citation:

Pym, A. (2021). Translation and language learning as policy options: Questions of costs and literacy development. TRANSLATION \& INTERPRETING-THE INTERNATIONAL JOURNAL OF TRANSLATION AND INTERPRETING, 13 (1), pp.24-37. https://doi.org/10.12807/ ti.113201.2021.a02.

Persistent Link:

http://hdl.handle.net/11343/281351

License:

CC BY 